\title{
Comparative studies on the microbial fermentations in the forestomachs of llamas and sheep
}

\author{
AM Smacchia 2, C Dardillat 1, Y Papon 1, JP Jouany ${ }^{1}$ \\ IINRA, Station de Recherches sur la Nutrition des Herbivores, Theix, 63122 St-Genès-Champanelle, France; \\ 2Universidad Nacional de Rosario, Facultad de Ciencas Veterinarias, Casilda, Argentina
}

Recent studies have shown that the organic matter digestibility of roughages was higher in llamas than in sheep (Dulphy et al, 1990, Ann Zootech, 43, 379-387). This is due to the higher cellulolytic activity of microbes in the forestomachs of Ilamas (Kayouli et al, 1993, Ann Zootech, 42, 184). The aim of the present study was to compare the in vitro production of microbial metabolites in the forestomach digesta sampled from 3 llamas $(L)$ and 3 sheep (S) fed a diet of hay ( $88 \%$ ) and concentrate $(12 \%)$, at daily intake levels of $1700 \mathrm{~g}$ and $1300 \mathrm{~g}$ respectively, given in two meals.

$650 \mathrm{ml}$ of digesta were manually removed from the dorsal sac through the rumen cannula of each animal 30 min after the evening meal and mixed for each type of animal; $200 \mathrm{ml}$ of the mixture were immediately introduced under $\mathrm{CO}_{2}$ into 8 ( 4 for $\mathrm{L}$ and 4 for $\mathrm{S}$ ) fermentors (see Jouany and Thivend, 1986, Anim Feed Sci Technol, 15, 215-229) each containing $200 \mathrm{ml}$ of $\mathrm{Mc}$ Dougall saliva and maintained at $39^{\circ} \mathrm{C}$. Fermentations were carried out for $17 \mathrm{~h}$. The experiment was repeated 6 times with digesta either mixed with saliva (M) or enclosed $(E)$ in a net ( $2 \mathrm{~mm}$ in mesh size) immersed in saliva to slow down the rate of fermentation.

Because the accessibility of microbes to feed particles was limited in "E" fermentors, $\mathrm{pH}$ was higher and the activity of fermentations was lower as assessed by FOM and gas productions. However, differences due to animals were not biased by the processing of digesta as indicated by the absence of any "animal x processing" interaction.

Comparisons between $\mathrm{L}$ and $\mathrm{S}$ showed that the digesta from $(L)$ had a higher DM content. FOM and production of gases were higher in $(L)(P<0.05)$. Also, the orientation of fermentations was changed since the molar proportions of butyrate and propionate were higher in (L) digesta. The gas composition was the same in $L$ and $S$. PH of digesta were not different between animals at the start or the end of incubations. The concentrations of $\mathrm{NH}_{3}-\mathrm{N}$ were always lower in (L) than in (S).

It can be concluded that the efficiency of the forestomach microbial ecosystem as assessed by the production of the major end products of fermentations is higher in (L) than in (S).

\begin{tabular}{|c|c|c|c|c|c|c|c|}
\hline \multirow{2}{*}{$\begin{array}{l}\text { Digesta } \\
\text { Animals }\end{array}$} & \multicolumn{2}{|c|}{ "M" in saliva } & \multicolumn{2}{|c|}{ "E" in a net } & \multirow{2}{*}{$\begin{array}{l}\text { "Animal" } \\
\text { effect }\end{array}$} & \multirow{2}{*}{$\begin{array}{c}\text { "Processing" } \\
\text { effect }\end{array}$} & \multirow{2}{*}{$\begin{array}{l}\text { "Interaction } \\
\text { "animal x } \\
\text { processing" }\end{array}$} \\
\hline & Sheep & Llama & Sheep & Llama & & & \\
\hline DM $(\%)$ & 12.6 & 14.2 & 13.1 & 14.1 & $\mathrm{~S}$ & - & - \\
\hline $\mathrm{pH}$ To, (T17) & $6.8(5.2)$ & $7.0(5.2)$ & $6.8(5.7)$ & $7.0(5.9)$ & (NS) & $(S)$ & (NS) \\
\hline $\mathrm{FOM}^{\mathrm{a}}(\mathrm{g} / 100 \mathrm{~g} \mathrm{DM})$ & 29.5 & 32.4 & 24.1 & 26.9 & $S$ & $\mathrm{~s}$ & NS \\
\hline Gases produced $(\mathrm{ml})^{b}$ & 57.0 & 57.6 & 46.6 & 48.0 & $s$ & $\mathrm{~s}$ & NS \\
\hline $\mathrm{CO}_{2} / \mathrm{CH}_{4}$ & 2.2 & 2.3 & 2.3 & 2.4 & NS & NS & NS \\
\hline $\mathrm{NH}_{3}-\mathrm{N}(\mathrm{mg} / \mathrm{l}) \mathrm{To},(\mathrm{T} 17)$ & $4.5(7.9)$ & $3.4(6.4)$ & $4.5(3.9)$ & $3.4(2.9)$ & (S) & (S) & (NS) \\
\hline
\end{tabular}

a FOM : fermented organic matter ; ${ }^{b}$ : expressed per $g$ of inoculum DM ; $\mathrm{S}: \mathrm{P}<0.05$. 